\title{
Infantile spasms in Down syndrome: a good response to vitamin $\mathrm{B} 6$
}

\author{
Roberto H. Caraballo, Ricardo O. Cersósimo, Fernanda Garro, Karina Kesler, Natalio Fejerman \\ Servicio de Neurología, Hospital de Pediatría “Prof. Dr. Juan P. Garrahan”, \\ Buenos Aires, Argentine
}

\begin{abstract}
We report the results of patients with Down syndrome (DS) and West syndrome (WS) treated with vitamin B6 and discuss the mechanisms of pyridoxine in WS. Twenty patients with DS and WS were referred to our service for infantile spasms (IS) between February 1990 and December 2002. WS was diagnosed on the basis of clinical and electroencephalogram features. Thirteen patients were treated conservately while seven patients (four girls and three boy) were treated according to the new alternative treatment scheme with vitamine B6. The dose of oral pyridoxine was between 200 and $400 \mathrm{mg} / \mathrm{day}$ $(25-50 \mathrm{mg} / \mathrm{kg} /$ day). Five patients initiated the treatment with vitamin B6 for IS two weeks and two patients four weeks after starting to receive antiepileptic drugs. One of them, who initially received intravenous pyridoxine $\mathbf{2 0 0}$ $\mathrm{mg} /$ day during three days with a partial control of IS, responded well to oral vitamin B6 400 $\mathrm{mg} / \mathrm{day}$ associated to valproic acid five months later. Mean age at the beginning of pyridoxine treatment was 9.5 months, ranging from 3 to 14 months. The time between the onset of spasms and vitamin $\mathrm{B} 6$ administration ranged from 2 to 4 weeks. Cessation of spasms was obtained within 2 weeks of treatment in four patients. Their electroencephalograms became normal as soon as the spasms disappeared. In four patients whose spasms ceased, pyridoxine was discontinued
\end{abstract}

Correspondence: Roberto Horacio Caraballo, M.D., Servicio de Neurología,

Hospital de Pediatría "Prof. Dr. Juan P Garrahan",

Combate de los Pozos 1881. CP 1245.

Buenos Aires. Argentina.

Tel-fax: 54-11-4943-6116.

E-mail: rcaraballo@jansen.com.ar

Received: September 19, 2003.

Revised: November 04, 2003.

Accepted: November 05, 2003. after 24 and 30 months and clinical spasms did not recur. These four children did not experience any other type of seizure after a mean time of follow-up of 6 years (range 1-10 years) without any type of treatment. In the fifth patient, cessation of spasms was obtained within four weeks the second time she received vitamin $B 6$, five months after the first treatment. She still receives with pyridoxine $400 \mathrm{mg} / \mathrm{day}(40 \mathrm{mg} / \mathrm{kg} /$ day) after twelve months of follow up and has had no spasms since. Two patients did not respond well either to pyridoxine or to vigabatrin, adrenocorticotropic hormone, valproic acid or benzodiazepines. The patients had no adverse events during treatment with pyridoxine. We consider an oral dose of 200-400 mg/day (25-50 $\mathrm{mg} / \mathrm{kg} / \mathrm{day}$ ) of pyridoxine either in monotherapy or combined with classic antiepleptic drugs to be the first choice of therapy in patients with IS and DS. Furthermore, patients who initially do not respond well to pyridoxine could be treated again and for a longer period. (J Pediatr Neurol 2004; 2(1): 15-19).

Key words: Down syndrome, infantile spasms, pyridoxine, vitamin B6, West syndrome.

\section{Introduction}

The prevalence of epilepsy in children with Down syndrome (DS) is estimated to be $1.4 \%$ and is considered to be not much higher than in the general population (1). The electroclinical features of epilepsy in DS patients have been well studied. $(2,3)$. Infantile spasms (IS) are the most common seizures observed (4-6). In a large series of children with West syndrome (WS), about 1\% had DS (7).

Neuropathological abnormalities are present in the brain of persons with DS $(8,9)$, and together with abnormal neuronal excitability they may lead to increased seizure susceptibility (10).

In 1940 the use of vitamin B6 in epilepsy was 
16

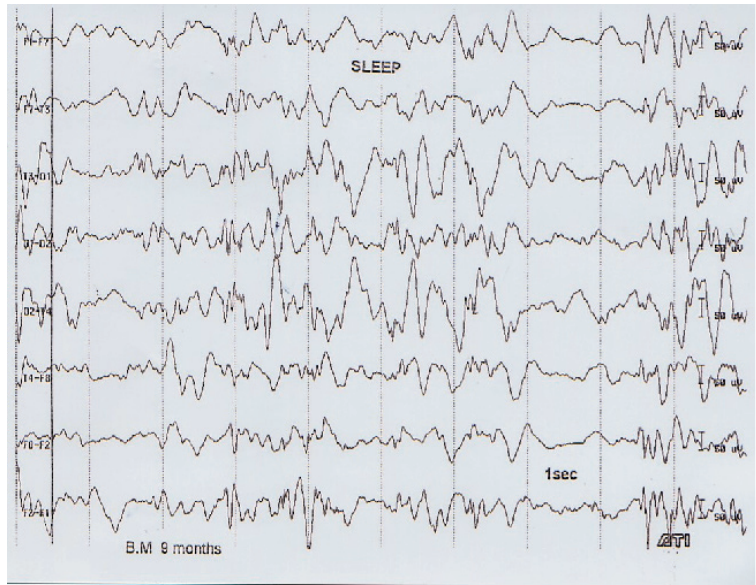

Figure 1. EEG during slow sleep shows hypsarrhythmia at nine months of age.

reported by Spies (11). Since then, several reports on B6 treatment in epilepsy have been published (12-14). In his recent book on vitamin responsive conditions, Baxter (15) discusses WS and pyridoxine in detail. Since Othahara first attempted to treat WS with high-dose vitamin B6 (16), it has been recognized as the treatment of choice in WS in Japan. In our previous study in 15 DS patients with WS, two responded well to vitamin B6 (17).

In this retrospective study, we report seven patients with DS and WS treated with vitamin B6 and discuss the mechanisms of vitamin B6 in WS.

\section{Materials and Methods}

Among 20 patients with DS and WS referred to the neuropediatric service of the Hospital Juan P. Garrahan, Buenos Aires, Argentina between February 1990 and December 2002. Thirteen patients were treated conservately with adrenocorticotropic hormone $(\mathrm{ACTH})$ in eight, combined with valproic acid in four of them, vigabatrin in four and vigabatrin plus valproic acid in the remaining one. Seven patients (four girls and three boys) were treated according to the new alternative treatment scheme with vitamine B6. Four of these seven patients had previously received vigabatrin and three $\mathrm{ACTH}$ but they did not respond well to the treatment. The antiepileptic drugs (AEDs) were stopped at initiation of B6. All of them had trisomy 21 and they were diagnosed during the first days of life due to dysmorphic features. They had no relevant personal and family history of febrile seizures or epilepsy. No other type of seizure was observed previous to the onset of IS. In all patients except one, a routine interictal electroencephologram (EEG) during sleep was performed before the onset of IS and in all patients an EEG recording was done before the beginning of treatment. Treatment with vitamin B6 for IS was initiated in five patients

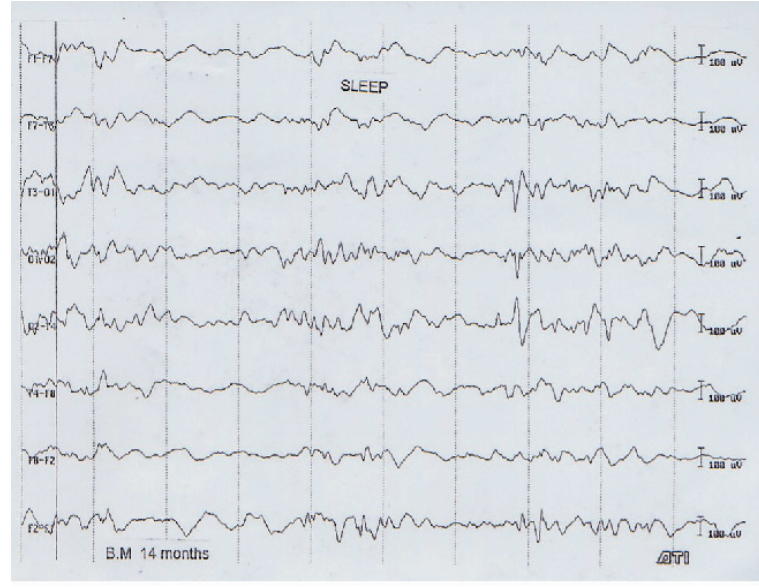

Figure 2. EEG during slow sleep shows similar electroclinical features at 14 months of age.

two weeks, and in two patients four weeks after starting to receive antiepileptic drugs. One of them who initially received pyridoxine $200 \mathrm{mg}$ per day (25 $\mathrm{mg} / \mathrm{kg} /$ day) intravenously during three days with a partial spasms control, responded well to oral vitamin B6 $400 \mathrm{mg}$ per day $(40 \mathrm{mg} / \mathrm{kg} /$ day $)$ associated with valproic acid $50 \mathrm{mg} / \mathrm{kg} /$ day five months later. Response assessment was based on cessation of spasms and disappearance of hypsarrhythmia and paroxysmal activity on interictal sleep EEG recordings and on parental report through a seizure diary. Video-EEG recordings were not registered in any of the patients.

\section{Results}

Clinical examination showed no abnormal signs other than the typical features of DS. The cerebral imaging (computerized tomography and magnetic resonance imaging) performed in all patients was also normal. EEGs performed before the onset of IS showed no abnormalities. The mean age at onset of spasms was 6.5 months (range, 3 to 11 months). All patients had symmetrical mixed (four patients) or flexor (three patients) spasms, occurring in clusters. The spasms were not recorded and interictal EEGs showed symmetric hypsarrhythmia in all patients. Pyridoxine treatment was started at a mean age of 9.5 months, ranging from 3 to 14 months. The time between the onset of spasms and vitamin B6 administration ranged from 2 to 4 weeks. The dose of oral pyridoxine was between 200 and 400 $\mathrm{mg} /$ day $(25-50 \mathrm{mg} / \mathrm{kg} / \mathrm{day})$. Cessation of spasms was obtained within 2 weeks of treatment in four patients.

Their EEGs became normal as soon as the spasms disappeared. In the other patient, EEG showed the hypsarrhythmia (Figure 1). She initially did not respond to a three-day course of intravenous pyridoxine $200 \mathrm{mg} / \mathrm{day}(25 \mathrm{mg} / \mathrm{kg} /$ day $)$. In spite of 
Table 1. Clinical features, treatment, and follow-up of patients with DS and WS

\begin{tabular}{|c|c|c|c|c|c|c|c|c|c|}
\hline $\begin{array}{l}\text { Case } \\
\text { no }\end{array}$ & $\begin{array}{l}\text { Age at } \\
\text { onset of } \\
\text { spasms } \\
\text { (month) }\end{array}$ & $\begin{array}{l}\text { Initial } \\
\text { EEG } \\
\text { findings }\end{array}$ & $\begin{array}{l}\text { Age at } \\
\text { treatment } \\
\text { with B6 } \\
\text { (month) }\end{array}$ & $\begin{array}{l}\text { Age at } \\
\text { spasm } \\
\text { cessation } \\
\text { (month) }\end{array}$ & $\begin{array}{l}\text { Dose } \\
\text { of } \\
\text { B6 } \\
(\mathrm{mg})\end{array}$ & $\begin{array}{l}\text { Age at B6 } \\
\text { disconti- } \\
\text { nuation } \\
\text { (month) }\end{array}$ & $\begin{array}{l}\text { Age at } \\
\text { last } \\
\text { control } \\
\text { (year) }\end{array}$ & $\begin{array}{l}\text { Seizures } \\
\text { at last } \\
\text { control }\end{array}$ & $\begin{array}{l}\text { EEG } \\
\text { at last } \\
\text { control }\end{array}$ \\
\hline 1 & 3 & $\begin{array}{l}\text { Modified } \\
\text { hypsarrhythmia }\end{array}$ & 3 & 3 & 200 & 18 & 6 & $\begin{array}{l}\text { Seizure- } \\
\text { free }\end{array}$ & Normal \\
\hline 2 & 7 & Hypsarrhythmia & 7 & 7.3 & 200 & 24 & 10 & $\begin{array}{l}\text { Seizure- } \\
\text { free }\end{array}$ & Normal \\
\hline 3 & 9 & Hypsarrhythmia & 9 & 9.25 & 200 & 24 & 10 & $\begin{array}{l}\text { Seizure- } \\
\text { free }\end{array}$ & Normal \\
\hline 4 & 5 & Hypsarrhythmia & 7.5 & 8 & 400 & 30 & 8 & $\begin{array}{l}\text { Seizure- } \\
\text { free }\end{array}$ & Normal \\
\hline $5 *$ & 7 & Hypsarrhythmia & 14 & 15 & 400 & $\begin{array}{l}\text { Still goes } \\
\text { on with } \\
\text { pyridoxine }\end{array}$ & 2.5 & $\begin{array}{l}\text { Seizure- } \\
\text { free }\end{array}$ & Normal \\
\hline 6 & 11 & Hypsarrhythmia & 11 & 24 & 200 & 12.5 & 6 & $\begin{array}{l}\text { Tonic } \\
\text { seizures }\end{array}$ & $\begin{array}{l}\text { Generalized } \\
\text { SW/PS-W }\end{array}$ \\
\hline 7 & 3 & $\begin{array}{l}\text { Modified } \\
\text { hypsarrhythmia }\end{array}$ & 4.5 & 30 & 200 & 5.5 & 9 & $\begin{array}{l}\text { Atonic } \\
\text { and } \\
\text { tonic } \\
\text { seizures }\end{array}$ & $\begin{array}{l}\text { Generalized } \\
\text { PS-W }\end{array}$ \\
\hline
\end{tabular}

* Second time this patient received pyridoxine.

SW: Spike-wave; PS-W: Polyspike-wave.

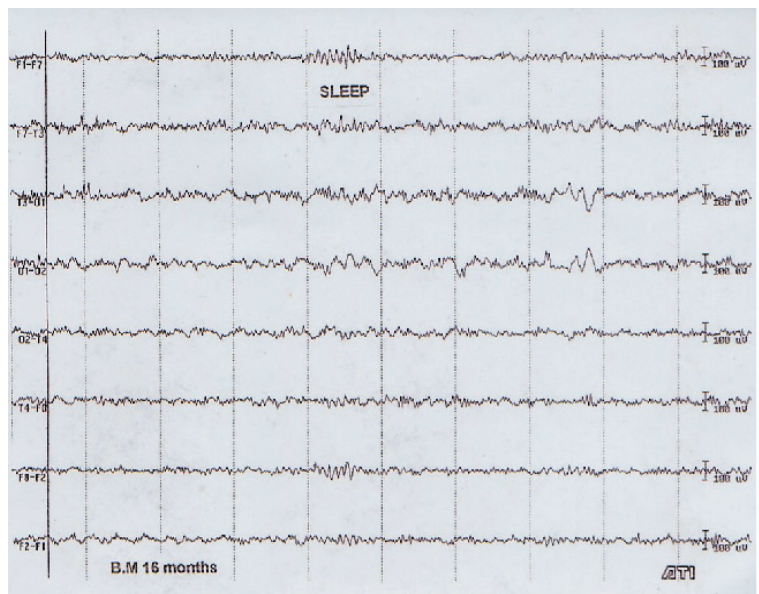

Figure 3. After the second treatment with oral pyridoxine, the EEG during slow sleep is normal at 16 months of age.

receiving different antiepileptic drugs, the IS could not be controlled. Five months later, at 14 months of age, the EEG still showed similar electroclinical features (Figure 2) and she started with oral pyridoxine $400 \mathrm{mg} /$ day $(40 \mathrm{mg} / \mathrm{kg} /$ day $)$, combined with valproic acid $50 \mathrm{mg} / \mathrm{kg} / \mathrm{day}$.

The spasms ceased at 15 months of age and EEG was normal at 16 months of age (Figure 3). Two patients did not respond well to either pyridoxine or vigabatrin, ACTH, valproic acid or benzodiazepines.

In four patients whose spasms ceased, pyridoxine was discontinued after 24 and 30 months and clinical spasms did not recur. These four children did not experience any other type of seizure after a mean time of follow-up of 6 years (range 1-10 years) without any type of treatment. The fifth patient continues taking pyridoxine $400 \mathrm{mg} /$ day $(40 \mathrm{mg}$ / $\mathrm{kg} /$ day) after 12 months of follow up and has had no spasms since. None of the patients had adverse events during treatment with pyridoxine. The main electroclinical features and follow up of our series are shown in Table 1.

\section{Discussion}

This study demonstrates a good response in $5 / 7$ patients with IS and DS who were treated with piridoxine. This group was compared to 13 patients treated with vigabatrin and ACTH. Seizure response was similar but side effects were greater in the second group. These results are in a published report (17)

A favorable outcome in patients with DS has been reported, but only in combination with vigabatrin and ACTH (17-21), despite the nonresponse to ACTH in the series of Romano et al (22).

Nabbout et al. (23) reported a good response to a short course of vigabatrin in patients with WS and DS, as four out of five children recovered from spasms. None of the responders experienced recurrence of spasms or any other type of seizures with a follow-up of between two and four years. 
This short course of vigabatrin might minimize the probable risk of developing visual field constriction. Many authors reported a good response to pyridoxine in patients with IS. The present series, however, is the first to show good response to pyridoxine in patients with both IS and DS (4,17).

Most authors found response to occur within a week or so but, duration of the treatment varied. Othsuka et al. (24) reported some response after a median of five days with a maximum of eleven and complete seizure control by a maximum of 16 days. In the present series of patients, cessation of spasms was obtained in four cases; after one week of treatment in two patients and within two weeks in the other two. The control EEG became normal as soon as the spasms disappeared in all four cases. In the fifth patient, spasms and hypsarrhythmia disappeared after one month of pyridoxine treatment combined with valproic acid. This patient received pyridoxine intravenously during three days after onset of IS but did not respond well to the drug.

Other authors used either low or high doses of pyridoxal phosphate or pyridoxine hydrocloride without showing significant difference in efficacy (25-27). Further studies would be necessary to elucidate the difference between the two types of vitamin $\mathrm{B} 6$ and dosage.

Only one long-term follow-up study has been reported in 25 patients with WS, 8 of whom with cryptogenic and 17 with symptomatic, who were responsive to vitamin B6. Twenty-one (84\%) of these patients continued to be seizure-free at the last visit (28). All cryptogenic and seven symptomatic WS patients had an IQ of 75 or higher. Pyridoxine therapy was discontinued without seizure relapse in four cryptogenic and in four symptomatic patients. EEGs showed no epileptic discharges in any of the responders. Four of our five patients did not have relapses either and the EEG showed no abnormalities after 24 to 30 months after pyridoxine therapy was discontinued.

The precise mechanism of pyridoxine in WS is unknown, but one hypothesis would be the influence of vitamin B6 on gamma aminobutiric acid (GABA), which is the main inhibitory neurotransmitter in the human central nervous system. Studies have shown that GABA levels in cerebrospinal fluid (CSF) in patients with WS are lower than in controls $(29,30)$. Furthermore, Kurlemann et al. (30) reported a patient in whom the GABA levels in CSF increased to within normal ranges after high-dose vitamin B6 therapy. The mechanism of pyridoxine in patients with WS and DS is not known either. High-dose vitamin B6 combined with standard agents has also been used in the treatment of WS. Two reports show successful treatment of WS with a combination of pyridoxal phosphate (40-50 $\mathrm{mg} / \mathrm{kg} /$ day) and low dosages of ACTH and a combination of vitamin B6 and valproic acid (25-31). The authors concluded that this last combination is more effective than valproic acid monotherapy in controlling WS.

The reported incidence of side effects associated with high-dose vitamin B6 is relatively high. Side effects include appetite loss, vomiting, diarrhea, constipation, hemorrhagic gastritis, liver dysfunction, marked abdominal flatulence, peripheral polyneuropathy and rhabdomyolisis (25). The most common side effects are gastrointestinal symptoms. Most of these side effects are mild and resolve after reduction or discontinuation of pyridoxine (25).

We could not find any factors predicting the response to pyridoxine, such as additional type of exogenous factors, type of chromosome anomalies or family history of seizure disorders.

In conclusion, because of rapid response without side effects within the first 2 weeks, we consider an oral dose of 200-400 mg/day (25-50 mg/kg/day) of pyridoxine as only treatment or in combination with classic AEDs to be an alternative choice of therapy in patients with IS and DS. Furthermore, patients who initially do not respond well to pyridoxine could be treated again and for a longer period. Taking into account the limitations of retrospective research, further studies are necessary to determine the optimal dosing schedule and to identify patients most likely to respond.

\section{References}

1. Tatsuno M, Hayashi M, Iwamoto H, Suzuki Y, Kuroki Y. Epilepsy in childhood Down syndrome. Brain Dev 1984; 6: 37-44.

2. Tsuboi T. Epilepsy and chromosomal aberrations. Epilepsia 1974; 15: 637 (abstract).

3. Stafstrom CE, Konkol RJ. Infantile spasms in children with Down Syndrome. Dev Med Child Neurol 1994; 36: 576-585.

4. Coriat LF, Fejerman N. Epilepsia en flexión generalizada en niños con trisomía 21. La semana médica en Pediatría 1969; 15: 493-500 (in French).

5. Pollack MA, Golden GS, Schmidt R, Davis JA, Leeds N. Infantile spasms in Down syndrome; a report of 5 cases and review of the literature. Ann Neurol 1978; 3: 406-408.

6. van Dyke DC, Lang DJ, Miller JD, Heide F, van Duyne S, Chang H. Common medical problems. In: van Dyke DC, Lang DC, Heide F, van Duyne S, Soucek MJ (eds). Clinical Perspectives in the Management of Down Syndrome. New York: Springer, 1990, pp 3-14.

7. Kurokawa T, Goya N, Fukuyama Y, Suzuki M, Seki T, Ohtahara S. West syndrome and Lennox-Gastaut syndrome: a survey of natural history. Pediatrics 1980; 65: 81-88.

8. Becker LE, Armstrong DL, Chan F. Dendritic atrophy in children with Down's syndrome. Ann Neurol 1986; 20: 520-526.

9. Wisniewski KE, Schimdt-Sidor B. Myelinitation 
in Down's syndrome brains (pre and post-natal maduration and some clinical-pathological correlations). Ann Neurol 1986; 20: 429-300.

10. Stafstrom CE. Epilepsy and Down syndrome: clinical aspects and possible mechanisms. Am J Ment Retard 1993; 98: 12-26.

11. Spies TD, Hightower DP, Hubbard IH. Some recent advances in vitamin therapy. J Ann Med Assoc 1940; 115: 292-297.

12. Ekelund H, Gamstorp I, Von Studnitz W. Apparent response of impaired development, minor motor epilepsy and ataxia to pyridoxine. Acta Paediatr Scand 1969; 58: 572-576.

13. Fox.JT, Tullidge GM. Pyridoxine in epilepsy. Lancet 1946; 2: 345 (abstract)

14. Livingston S, Jeng MH, Petersen DC. Ineffectiveness of pyridoxine (vitamin B6) in treatment of epilepsy. Pediatrics 1955; 16: 250-251.

15. Baxter P. Vitamin Responsive Conditions in Paediatric Neurology. International Child Neurology Association: Mac Keith Press, 2001.

16. Ohtahara S, Ohtsuka Y, Yamatogi Y, Oka E. The early-infantile epileptic encephalopathy with suppression-bursts: developmental aspects. Brain Dev 1987; 9: 371-376.

17. Caraballo R, Cersósimo R, Arroyo H, Fejerman N. Síndrome de West sintomático: asociaciones etiológicas particulares con respuesta inesperada al tratamiento. Rev Neurol (Barc) 1998; 26: 372-375 (in Spanish).

18. Pollack MA, Golden GS, Schmidt R. Infantile spasms in Down syndrome: a report of 5 cases and review of the literature. Ann Neurol 1978; 3: 406408.

19. Cassidy S, Gainey A, Holmes G. Infantile spasms in Down syndrome: an appreciated association. Am J Hum Genet 1983; 35: 82 (abstract).
20. Marks WA, Readen S, Wilson S. Infantile spasms in Down syndrome. Epilepsia 1990; 31: 664 (abstract).

21. Escofet C, Poo P, Valbuena 0, Gassio R, Sanmarti FX. Campistol J. Infantile spasm in children with Down's syndrome. Rev Neurol 1995; 23: 315-317 (in Spanish).

22. Romano C, Tiné A, Fazio G et al. Seizures in patients with trisomy 21. Am J Med Genet 1990; Suppl 7: 298-300.

23. Nabbout R, Melki I, Gerbaka B, Dulac O, Akatcherian C. Infantile spasms in Down syndrome: good response to a short course of vigabatrin. Epilepsia 2001; 42: 1580-1583.

24. Ohtsuka Y. Matsuda M, Ogino T. Kobayashi K. Ohtahara S. Treatment of West syndrome with highdose pyridoxal phosphate. Brain Dev 1987; 9: 418421.

25. Toribe Y. High-dose vitamin B6 treatment in West syndrome. Brain Dev 2001; 23: 654-657.

26. Blennow G, Starck L. High dose B6 treatment in infantile spasms. Neuropediatrics 1986; 17: 7-10.

27. Pietz J, Benninger C, Schafer H, Sontheimer D, Mittermaier G, Rating D. Treatment of infantile spasms with high-dosage vitamin B6. Epilepsia 1993; 34: 757-763.

28. Ohtsuka Y, Ogino T, Asano T, Hattori J, Ohta H, Oka E. Long-term follow up of vitamin B6-responsive West syndrome. Pediatr Neurol 2000; 23: 202-206.

29. Ito M, Mikawa H, Taniguchi T. Cerebrospinal fluid GABA levels in children with infantile spasms. Neurology 1984; 34: 235-238.

30. Kurlemann G, Deufel T, Schuierer G. Pyridoxineresponsive West syndrome and gamma-aminobutiric acid. Eur J Pediatr 1997; 156: 158-159.

31. Ito M, Okuno $\mathrm{T}$, Hattori $\mathrm{H}$, Fujii $\mathrm{T}$, Mikawa $\mathrm{H}$. Vitamin B6 and valproic acid in treatment of infantile spasms. Pediatr Neurol 1991; 7: 91-96. 